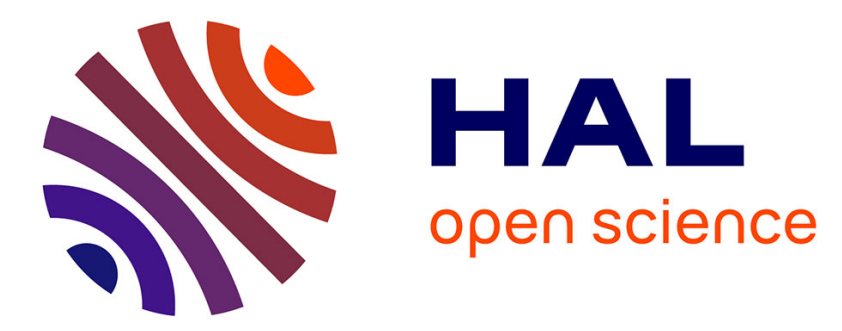

\title{
Electrochemistry of cytochrome c immobilized on cardiolipin-modified electrodes: a probe for protein - lipid interactions
}

Antoine Perhirin, Edouard Kraffe, Yanic Marty, Francois Quentel, Philippe Elies, Frederic Gloaguen

\section{To cite this version:}

Antoine Perhirin, Edouard Kraffe, Yanic Marty, Francois Quentel, Philippe Elies, et al.. Electrochemistry of cytochrome c immobilized on cardiolipin-modified electrodes: a probe for protein - lipid interactions. BBA - Biochimica et Biophysica Acta, 2013, 1830 (3), pp.2798-2803. 10.1016/j.bbagen.2012.12.009 . hal-01130700

\section{HAL Id: hal-01130700 \\ https://hal.univ-brest.fr/hal-01130700}

Submitted on 12 Mar 2015

HAL is a multi-disciplinary open access archive for the deposit and dissemination of scientific research documents, whether they are published or not. The documents may come from teaching and research institutions in France or abroad, or from public or private research centers.
L'archive ouverte pluridisciplinaire HAL, est destinée au dépôt et à la diffusion de documents scientifiques de niveau recherche, publiés ou non, émanant des établissements d'enseignement et de recherche français ou étrangers, des laboratoires publics ou privés. 
NOTICE: This is the author's version of a work accepted for publication by Elsevier.

Changes resulting from the publishing process, including peer review, editing, corrections, structural formatting and other quality control mechanisms, may not be reflected in this document. Changes may have been made to this work since it was submitted for publication. A subsequent version will be published in BBA and will be available at http://dx.doi.org/10.1016/j.bbagen.2012.12.009

\section{Electrochemistry of cytochrome $c$ immobilized on cardiolipin-modified electrodes: a} probe for protein - lipid interactions

Antoine Perhirin ${ }^{\mathrm{a}}$, Edouard Kraffe ${ }^{\mathrm{b}}$, Yanic Marty ${ }^{\mathrm{a}}$, François Quentel ${ }^{\mathrm{a}}$, Philippe Elies ${ }^{\mathrm{c}}$, Frederic Gloaguen ${ }^{\mathrm{a} *}$

${ }^{\mathrm{a} C E M C A, ~ U M R ~ 6521 ; ~}{ }^{\mathrm{b}} \mathrm{LEMAR}, \mathrm{UMR}$ 6539; ${ }^{\mathrm{c}}$ Plateforme d'Imagerie et de Mesure en Microscopie; CNRS; Université de Bretagne Occidentale; Brest, France E-mail:kraffe@univ-brest.fr (EK) ; fgloague@univ-brest.fr (FG)

\footnotetext{
Abstract

Electrochemistry of cytochrome $c$ (cyt $c$ ) immobilized on a cardiolipin (CL) / phosphatidylcholine (PC) film supported on a glassy carbon electrode was investigated using variable-frequency AC voltammetry. At low ionic strength, we observed two redox-active subpopulations characterized by distinct values of potential $\left(E_{1 / 2}\right)$ and electron transfer rate constant $\left(k_{\mathrm{ET}}\right)$. At high ionic strength, only one subpopulation was detected, consistent with the existence of very stable cyt $c-$ CL adducts, most probably formed by hydrophobic interactions between the protein and the fatty acid (FA) chains carried by CL. This subpopulation exhibits a comparatively high $k_{\mathrm{ET}}$ value $\left(>300 \mathrm{~s}^{-1}\right)$ apparently changing with the structure of the FA chains of CL, i.e. 18:2(n-6) or 14:0. Our study suggests that
} 
electrochemistry can be a useful technique for probing protein - lipid interactions, and more particularly the role played by the specific structure of the FA chains of CL on cyt $c$ binding.

Keywords: Cardiolipin; Cytochrome $c$; Electron transfer, Fatty acid chain; Lipid anchorage; Voltammetry

\section{Introduction}

Probing protein - lipid interactions is of considerable interest to gain basic understanding of structure - function relationships in biological membranes [1,2], but also to control the construction of hybrid biological - inorganic objects [3, 4]. Cytochrome $c$ (cyt $c)$ is a water-soluble protein involved in the respiratory chain of mitochondria [5]. The heme group of cyt $c$ shuttles electrons from cyt $c$ reductase to cyt $c$ oxidase. Cardiolipin (CL) is an essential component of the inner mitochondrial membrane [6]. This negatively charged phospholipid bears two phosphate moieties and four fatty acid (FA) chains of length ranging from 14 to 22 carbon atoms. CL plays a key role in maintaining optimal activity of numerous mitochondrial processes, such as electron transfer and ADP/ATP translocation [7], but also cell apoptosis [8]. The specific structure of FA chains seems to be an important requirement for biological functions of CL [9]. Interactions between cyt $c$ and CL have been extensively investigated using liposomes $[10,11]$. At neutral $\mathrm{pH}$, cyt $c$ holds a positive charge of $c a .+7$ (the actual charge depends on the organism from which it derives), whereas CL carries a negative charge of -1 [12] explaining the occurrence of electrostatic interaction between this two physiological partners. In addition, evidence for the formation of cyt $c-\mathrm{CL}$ adducts stabilized by hydrogen bonding and hydrophobic interactions at specific sites on the protein scaffold have been reported $[13,14]$. According to the so-called lipid anchorage theory [13, 
15-18], one or two FA chains of CL find a place into a large hydrophobic channel of cyt $c$, which extends from the surface of protein to the neighborhood of the heme group, while the other FA chains remains within the mitochondrial lipid layer to secure the binding.

The direct electrochemical reduction of cyt $c$ is irreversible at most conventional electrodes [19]. Reversible electron transfer (ET) between the heme group of cyt $c$ and the electrode has however been achieved using surface modifiers such as bipyridine adsorbed on gold [19] or self-assembled monolayers (SAMs) [3, 20]. In addition, the redox properties of cyt $c$ immobilized on negatively charged SAMs has been used as a probe of the protein conformation and/or orientation [21-24]. Both the redox potential and the ET rate depend on the structure of the molecules composing the SAMs. Lipid films containing CL have also been used to mediate ET between cyt $c$ and the electrode supporting the film [25-28]. As seen for negatively charged SAMs, electrostatic interaction between cyt $c$ and a CL-modified electrode is believed to permit the binding of the protein in an orientation allowing ET [27]. Another possibility is the formation of cyt $c-\mathrm{CL}$ adducts stabilized by lipid anchorage, but this hypothesis remains to be tested.

The objective of the present study was to determine whether electrochemistry of cyt $c$ immobilized on a lipid-modified electrode could provide insights on the interactions between cyt $c$ and CL. This approach requires precise measurements of the redox properties of CLbound cyt $c$. To this aim, instead of cyclic voltammetry $(\mathrm{CV})$, we used the variable-frequency $\mathrm{AC}$ voltammetry (ACV) method developed by Creager and coworkers $[29,30]$ allowing the study of small amounts of immobilized redox centers transferring electrons at different potentials and rates. Finally, the role played by hydrophobic interaction on electrochemistry of CL-bound cyt $c$ was probed using electrodes modified by CL carrying either saturated or unsaturated FA chains, i.e. myristic acid (14:0) or linoleic acid (18:2(n-6)). 


\section{Materials and methods}

\subsection{Materials}

Natural soybean phosphatidylcholine (PC) with FA of composition 18:2(n-6) (66.8\%), 16:0 (14.7\%) and 18:1(n-9) (7.1\%), and 1,1',2,2'-tetramyristoyl cardiolipin (CL14:0) were obtained from Avanti Polar Lipids. 1,1',2,2'-tetralinoleoyl cardiolipin (CL18:2(n-6)) was purchased from Sigma. Lipids were purified using high performance liquid chromatography (HPLC), and then dissolved in chloroform/methanol mixture $(98 / 2 \mathrm{v} / \mathrm{v})$ to prepare ca. $0.1 \mu \mathrm{g}$

$\mu \mathrm{L}^{-1}$ solutions containing $\mathrm{CL}$ and $\mathrm{PC}$ in a 20/80 molar ratio. Exact lipid concentration was determined by quantitative analysis of FA using FA23:0 as an internal standard [31]. Briefly, after addition of $\mathrm{BF}_{3}$ in $\mathrm{CH}_{3} \mathrm{OH}(0.8 \mathrm{~mL}, 14 \% \mathrm{w})$ and butylated hydroxytoluene $(0.01 \% \mathrm{w} / \mathrm{w})$ as antioxidant, the lipids were transesterified by heating at $100{ }^{\circ} \mathrm{C}$ during $10 \mathrm{~min}$. The amount of FA methyl esters was measured using a gas chromatograph equipped with an on-column injector and a flame-ionization detector. Cyt $c$ from bovine heart provided by Sigma was used without additional purification. All other reagents were of the highest purity available. Solutions containing cyt $c(50 \mu \mathrm{M})$ and TRIS-HCl buffer $(20 \mathrm{mM}, \mathrm{pH} 7.0)$ were prepared using deionized water coming from a MilliQ Millipore system. EDTA (1 mM) was added to prevent divalent cation substitution [28]. Protein solutions were stored at $4{ }^{\circ} \mathrm{C}$ and discarded when older than one week.

\subsection{Preparation of lipid-modified electrodes}

The electrode supporting the lipid film was a glassy carbon (GC) rotating disk electrode of $0.071 \mathrm{~cm}^{2}$ (Metrohm) polished with alumina to a mirror finish, cleaned in water using an ultrasound bath, and rinsed with acetone. Several drops ( $c a .2 \mu \mathrm{L})$ of lipid solution 
were deposited on the GC disk to obtain a total amount of $1 \mu \mathrm{g}$ of lipids. Solvents were then evaporated by rotation of the electrode at $500 \mathrm{rpm}$.

\subsection{Electrochemical measurements}

Electrochemical experiments were carried out in a standard three-electrode cell at the controlled temperature of $25 \pm 0.1{ }^{\circ} \mathrm{C}$. The reference electrode was a saturated calomel electrode (SCE) and the counter electrode a platinum wire. Voltammetric data were recorded using a potentiostat (PGSTAT30A, Autolab) equipped with a FRA additional module. To immobilize cyt $c$ on the lipid film, the electrode was immersed in an argon-purged cyt $c$ solution and cycled between 0.3 and $-0.3 \mathrm{~V} v s$. SCE at a scan rate of $50 \mathrm{mV} \mathrm{s}^{-1}$ (Fig. S1 in supplementary data). Then, the electrode was gently washed with argon-purged TRIS-HCl buffer solution $(20 \mathrm{mM}, \mathrm{pH} 7)$ and transferred to a second cell containing the same buffer solution but no cyt $c$. Measurements of the redox potential $\left(E_{1 / 2}\right)$ and ET rate of cyt $c$ immobilized on the lipid-modified electrode was carried out using the frequency-variable ACV method developed by Creager and coworkers [29, 30]. ACV experiments at high frequencies showed two redox peaks. As a result, for each peak potential, a plot of the background corrected peak current against the logarithm of the frequency was fitted using an equivalent circuit, which simulates an electrode modified by adsorbed redox species exhibiting a distribution of ET rate constants. This procedure gave us the value of the ET rate constant $\left(k_{\mathrm{ET}}\right)$ and coverage $(\Gamma)$ of each cyt $c$ subpopulation (see supplementary data for further details). Electrochemical measurements were repeated at least four times with each time a completely new lipid-modified electrode. The mean values of $E_{1 / 2}, k_{\mathrm{ET}}$ and $\Gamma$ thus obtained were statistically compared using Statgraphics 5.1+ software. Analysis of variance (ANOVA) was carried out using the post-hoc Fisher's least significant difference test. ANOVA was performed as long as criteria of normality and homogeneity of variances were 
respected. For data set not following criterion of normality, non parametric Kruskall-Wallis ANOVA was performed. For each group of means tested, differences were considered as significant when P-value $<0.05$.

\subsection{Atomic force microscopy images}

Images of the GC electrode and the lipid film were obtained under ambient condition using a multimode AFM (Nanoscope V, Digital Instruments, Veeco). Tapping mode was used to reduce the potentially destructive lateral forces exerted on the lipid film. Topographic and error amplitude images were simultaneously recorded using commercial silicon probes of nominal radius $<10 \mathrm{~nm}$ (TAP150, Veeco) and cantilevers of spring constant of $5 \mathrm{~N} \mathrm{~m}^{-1}$ and resonant frequency of $20 \mathrm{kHz}$ (MPP12100, Nanodevices).

\section{Results and Discussion}

\subsection{Characterization and stability of the supported lipid film}

Unless otherwise noted, the lipid film was composed of PC and either CL 14:0 or CL18:2 in 80/20 molar ratio to mimic the mitochondrial membrane composition [6]. This choice is furthermore justified by the finding that cyt $c$ interacts more favorably with CL when the latter is mixed with PC [32]. Besides, we verified that a GC electrode covered with a film of pure PC does not efficiently exchange electrons with cyt $c$ (Fig. S2 in supplementary data) [26].

The good quality of the CL/PC film coating the GC electrode was confirmed by inspection of the AFM images recorded on the same spot before and after evaporation of a drop of lipid solution. As shown in Fig. 1, the surface is fully covered by lipids forming most 
certainly a monolayer. Small patches on the top of the lipid film can also be observed. Since the relative height of these patches is $c a .2 \mathrm{~nm}$, they are ascribed to the formation of a bilayer.

The coating of the GC electrode by the lipid film was additionally checked using $\mathrm{Fe}(\mathrm{CN})_{6}{ }^{3-}$ as a redox probe (Fig. S3 in supplementary data). As expected, the electrochemical signal of this anion in TRIS-HCl buffer solution ( $\mathrm{pH} 7)$ is mostly suppressed after modification of the GC electrode with a negatively charged lipid film. This redox behavior points to the successful formation of a lipid film covering the entire electrode surface. We however note that the current - potential response is not flat but takes the shape of a wave, as would be observed in the case of an array of microelectrodes, suggesting the existence of pinholes [33]. Small defects in the lipid film are without consequences for the study of the electrochemistry of immobilized cyt $c$, since there is no direct ET between the protein and a bare GC electrode (vide infra).

The stability of the lipid film under electrochemical conditions was verified by redissolution of the lipids in chloroform at the end of a series of measurements. Quantitative analysis by gas chromatography indicated that less than $20 \%$ of the amount initially deposited was lost after a period of two hours, emphasizing the good stability of the lipid-modified electrode. In a previously reported study, CL was mixed with cholesterol to improve the stability of the lipid film during long-time electrochemical measurements [27]. This method was found unnecessary because of the stability of our lipid film, and was disregarded as the presence of cholesterol could alter the interactions between CL and cyt $c$.

\subsection{Electrochemistry of cyt c at CL/PC-modified electrode}

We first verified by CV that there is no ET between cyt $c$ in solution and a bare GC electrode (Fig. 2) [27]. After modification of the GC electrode with a CL/PC film, CV shows reversible redox peaks ascribed to the reduction and the oxidation of the heme group of cyt $c$. 
In the course of potential cycling, the redox peaks develop in height, eventually reaching a maximum value after a period of 5-10 min (Fig. S1 in supplementary data). This electrochemical response indicates that saturation coverage of cyt $c$ on the lipid film is achieved. During the cycling procedure, the half-peak potential is slightly shifted toward negative values, consistent with previous observations $[22,34]$. As shown in Fig. 2, the halfpeak potential of the heme group of cyt is $E_{1 / 2}=-11 \mathrm{mV} v s$. SCE with a peak-to-peak separation $\Delta E_{\mathrm{p}}=44 \mathrm{mV}$ at a scan rate of $50 \mathrm{mV} \mathrm{s}^{-1}$, in good agreement with the voltammetric data measured under similar conditions at a CL-modified graphite electrode [28].

The voltammograms recorded after the transfer of the CL/PC-modified electrode saturated with surface-confined cyt $c$ in a cell containing no protein clearly show a signal lost (Fig. 2), indicating that the amount of cyt $c$ in the vicinity of the electrode has significantly decreased. The most possible explanation is that free-diffusing cyt $c$ is able to exchange electrons with the electrode through the lipid film, hence the large signal in solution containing protein. In addition, removal of surface-confined protein loosely interacting with the lipid film is very likely during the transfer procedure. The methodology used here is therefore suitable to limit the electrochemical measurements to the fraction of cyt $c$ that interacts either electrostatically or hydrophobically with the lipid film.

$\mathrm{CV}$ of immobilized cyt $c$ shows redox peaks spanning over a large potential range (Fig. 2). In contrast, the ACV displays a sharp peak that can be easily discriminated from the background current (Fig. 3). The ACV measured at the frequency of $4 \mathrm{~Hz}$ shows a peak for immobilized cyt $c$ centered at about $-20 \mathrm{mV} v s$. SCE. The formal potential of cyt $c$ in solution is $E_{1 / 2, \text { sol }} \approx+15 \mathrm{mV} v s$. SCE. Although the measured redox potential for immobilized cyt $c$ varies with the electrode material and the nature of the modifier, electrochemical and spectroscopic studies have shown that a large potential shift up to $-0.4 \mathrm{~V}$ relative to $E_{1 / 2 \text {,sol }}$ may be associated with large modification of the protein structure away of its native state 
[35]. Here the potential is only slightly downshifted by relative to that in solution, as in the case of gold electrodes coated with alkanethiols terminating in carboxylic acid groups [20], which indicates that cyt $c$ immobilized on the lipid film is not denaturated.

A full monolayer of cyt $c$ would correspond to a surface concentration of about 15 pmol of protein per $\mathrm{cm}^{2}$ [23]. The surface concentrations measured by ACV were 5.2 and 8.1 pmol $\mathrm{cm}^{-2}$ for CL14:0 and 18:2, corresponding to a theoretical surface coverage of $35 \%$ and $54 \%$, respectively (Table 1). We however note that the actual surface coverage of immobilized protein should be significantly lower since the roughness factor of the glassy carbon electrode largely exceeds unity (see AFM images in Fig. 1).

\subsection{Evidence for two subpopulations of immobilized cyt $c$}

Five representative ACVs acquired at frequencies ranging from 4 to $692 \mathrm{~Hz}$ for cyt $c$ immobilized on a CL/PC-modified electrode are shown in Fig. 3. At low frequencies, there is one redox peak centered at about $-20 \mathrm{mV}$. The peak current rapidly decreases with increasing the frequency, indicating that the redox process under scrutiny cannot exchange electrons rapidly. At frequencies exceeding $30 \mathrm{~Hz}$, a new redox peak centered at about $-130 \mathrm{mV}$ appears. The height of this second peak is much less responsive to frequency increase, indicating a fast ET process. This electrochemical behavior, which was observed at both CL14:0/PC- and CL18:2/PC-modified electrodes, can only be explained by the existence of two independent subpopulations of immobilized redox molecules exhibiting different redox potentials and ET rates. Additional support for this assumption was obtained from the plot of the background corrected ACV current at $-50 \mathrm{mV}$ against the logarithm of the frequency, on which two distinct sigmoids centered respectively below $1 \mathrm{~Hz}$ and above $100 \mathrm{~Hz}$ could be clearly observed (Fig. S4 in supplementary data) [29, 30]. 
The redox potential $\left(E_{1 / 2}\right)$, and corresponding ET rate constant $\left(k_{\mathrm{ET}}\right)$ and protein coverage $(\Gamma)$, calculated from the ACV measurements for each subpopulation are listed in Table 1 (see also Figs. S5 and S6 in supplementary data). Cyt $c$ of subpopulation 1, which represents the majority of immobilized protein, is characterized by a comparatively slow ET rate at a potential close to that of the protein in solution. In contrast, cyt $c$ of subpopulation 2 exchanges electrons at high rate, but at a redox potential negatively shifted by more than 100 $\mathrm{mV}$. Shift in reduction potentials appears thus to parallel the strength of interactions between cyt $c$ and the lipid film. Numerous studies using liposomes have reported the existence of two subpopulations of cyt $c$ bound to CL [14, 18, 25, 36, 37]. In most cases, it has been shown that about $90 \%$ of the total amount correspond to electrostatically-bound cyt $\mathrm{c}$, while the remaining $10 \%$ correspond to hydrophobically-bound cyt $c$. In our work, subpopulation 2 , which is the less abundant, was calculated to represent respectively $15 \%$ for CL14:0/PC and $5 \%$ for CL18:2/PC of the total coverage of immobilized cyt $c$. After extensive washing of the electrode with a high ionic strength solution (i.e. $0.5 \mathrm{M} \mathrm{KCl}$ ), the signal corresponding to subpopulation 1 is almost suppressed, while that corresponding to subpopulation 2 remains mainly unchanged (Fig. 4). These observations strongly suggest that subpopulation 2 is composed of very stable cyt c - CL adducts formed by hydrophobic interactions, whereas subpopulation 1 corresponds to cyt $\mathrm{c}$ interacting mainly electrostatically with CL.

The ET rates measured for cyt $c$ of subpopulation 2 are order of magnitudes larger to that measured with cyt $c$ electrostatically immobilized on SAM formed by a thiol spacer comprising a similar number of carbon atoms [23]. Although insertion of cyt $c$ into the lipid film might occur, 'simple' distance-dependent electron tunneling process cannot explain the magnitude of the ET rate measured for subpopulation 2 at the lipid-modified electrodes [38]. The most likely assumption is that formation of stable cyt $\mathrm{c}-\mathrm{CL}$ adducts modifies the orientation of the protein relative to the electrode surface and/or the coordination sphere of the 
iron ion in the heme group, hence accelerating the ET rate. Indeed, replacement of the amino acid axially coordinating the heme group of immobilized cyt $c$ has been shown to have a pronounced effect on the ET rate [35].

\subsection{Dependence of the ET rate on the nature of $C L$}

For subpopulation 1, it seems at first sight that the average rate constant is slower at CL18:2/PC- than CL14:0/PC-modified electrode ( $k_{\mathrm{ET}}=8 \pm 2 \mathrm{~s}^{-1}$ and $30 \pm 11 \mathrm{~s}^{-1}$, respectively) (Table 1). Nevertheless, statistical analysis of these mean values showed that the difference is not significant $(\mathrm{P}$-value $=0.18)$, leading to the conclusion that there is no influence of the nature of the CL on the redox properties of cyt $c$ composing subpopulation 1 .

Cyt $c$ composing subpopulation 2 behaves differently. Mean values of $k_{\mathrm{ET}}$ showed that there is for the subpopulation 2 an effect of the nature of the CL composing the lipid film (Pvalue $=0.002)$. The ET rate is twice faster at a CL18:2/PC- than at CL14:0/PC-modified electrode. This results points to an effect of the structure of the FA chains on the ET rate of cyt $c$ composing subpopulation 2. Evidence for specific interactions between the double carbon bonds in the FA chains of CL and bound cyt $c$ has been obtained by spectroscopic methods [36]. According to the lipid anchorage theory, one or two FA chains are brought in close vicinity to the heme group of cyt $c$. Our study tends to show that such interaction might provide a more favorable pathway for ET in the case of 18:2(n-6) FA chains holding double carbon bonds at specific locations. This assumption is yet speculative and additional electrochemical experiments using CL carrying 18:0 and 18:1 FA chains are needed to address more precisely this issue, and more broadly the question of the biological function of atypical FA chain composition in CL of eukaryotes.

\section{Conclusions}


Prior to our work, there have been several studies on the electrochemistry of cyt $c$ at electrodes modified by phospholipids. However the main goal was to measure the rate of ET under various conditions of $\mathrm{pH}$ and ionic strength, without any particular interest to the biophysical properties and the biological functions of the phospholipids.

Herein, lipids were carefully analyzed and the lipid film was composed of CL and PC in a 20/80 molar ratio to mimic the mitochondrial membrane composition. Using ACV, we were able to characterize two subpopulations of cyt $c$ bound to CL, a result that could not be obtained using classical CV techniques. At high ionic strength, only one subpopulation remained detected, consistent with the existence of very stable cyt $\mathrm{c}-\mathrm{CL}$ adducts, most probably formed by hydrophobic interactions. This assumption was further supported by the high $k_{\mathrm{ET}}$ values $\left(>300 \mathrm{~s}^{-1}\right.$ ) measured for this cyt $c$ subpopulation. This finding allowed us to analyze more finely the influence of CL on the electrochemistry of cyt c. We found that the ET rate of hydrophobically-bound cyt $c$ is twice faster at a CL18:2/PC- than at a CL14:0/PCmodified electrode. Our study suggests that electrochemistry might be a useful technique for probing protein - lipid interactions, and particularly the role played by the specific structure of FA chains on conformation and orientation of cyt $c$ bound to CL.

\section{Acknowledgement}

We thank Université de Bretagne Occidentale (UBO) and Centre National de Recherche Scientifique (CNRS) for their financial support and AP thanks UBO for a PhD thesis grant.

\section{References}


[1] D. Marsh, Lipid-protein interactions in membranes, FEBS Lett., 268 (1990) 371-375.

[2] O.S. Andersen, R.E. Koeppe, Bilayer Thickness and Membrane Protein Function: An Energetic Perspective, Annu. Rev. Biophys. Biomol. Struct., 36 (2007) 107-130.

[3] M. Mrksich, G.M. Whitesides, Using self-assembled monolayers to understand the interactions of man-made surfaces with proteins and cells, Annu. Rev. Biophys. Biomol. Struct., 25 (1996) 55-78.

[4] S. Mann, Self-assembly and transformation of hybrid nano-objects and nanostructures under equilibrium and non-equilibrium conditions, Nat. Mater., 8 (2009) 781-792.

[5] M. Fedurco, J. Augustynski, C. Indiani, G. Smulevich, M. Antalik, M. Bano, E. Sedlak, M.C. Glascock, J.H. Dawson, Electrochemistry of unfolded cytochrome c in neutral and acidic urea solutions, J. Am. Chem. Soc., 127 (2005) 7638-7646.

[6] G. Daum, Lipids of mitochondria, Biochim. Biophys. Acta, 822 (1985) 1-42.

[7] M. Schlame, D. Rua, M.L. Greenberg, The biosynthesis and functional role of cardiolipin, Prog. Lipid Res., 39 (2000) 257-288.

[8] X. Liu, C.N. Kim, J. Yang, R. Jemmerson, X. Wang, Induction of Apoptotic Program in Cell-Free Extracts: Requirement for dATP and Cytochrome c, Cell, 86 (1996) 147-157.

[9] M. Schlame, S. Brody, K.Y. Hostetler, Mitochondrial cardiolipin in diverse eukaryotes, Eur. J. Biochem., 212 (2005) 727-733.

[10] T.J.T. Pinheiro, The interaction of horse heart cytochrome c with phospholipid bilayers. Structural and dynamic effects, Biochimie, 76 (1994) 489-500.

[11] J. Hanske, J.R. Toffey, A.M. Morenz, A.J. Bonilla, K.H. Schiavoni, E.V. Pletneva, Conformational properties of cardiolipin-bound cytochrome c, Proc. Natl. Acad. Sci. U.S.A., 109 (2012) 125-130.

[12] M. Kates, J.-Y. Syz, D. Gosser, T. Haines, pH-dissociation characteristics of cardiolipin and its 2'-deoxy analogue, Lipids, 28 (1993) 877-882. 
[13] M. Rytömaa, P. Mustonen, P.K. Kinnunen, Reversible, nonionic, and pH-dependent association of cytochrome c with cardiolipin-phosphatidylcholine liposomes, J. Biol. Chem., 267 (1992) 22243-22248.

[14] J.D. Cortese, A.L. Voglino, C.R. Hackenbrock, Persistence of cytochrome c binding to membranes at physiological mitochondrial intermembrane space ionic strength, Biochim. Biophys. Acta, 1228 (1995) 216-228.

[15] M. Rytömaa, P.K. Kinnunen, Evidence for two distinct acidic phospholipid-binding sites in cytochrome c, J. Biol. Chem., 269 (1994) 1770-1774.

[16] M. Rytömaa, P.K.J. Kinnunen, Reversibility of the Binding of Cytochrome c to Liposomes, J. Biol. Chem., 270 (1995) 3197-3202.

[17] E.K.J. Tuominen, C.J.A. Wallace, P.K.J. Kinnunen, Phospholipid-Cytochrome c Interaction, J. Biol. Chem., 277 (2002) 8822-8826.

[18] F. Sinibaldi, B. Howes, M. Piro, F. Polticelli, C. Bombelli, T. Ferri, M. Coletta, G. Smulevich, R. Santucci, Extended cardiolipin anchorage to cytochrome c: a model for protein-mitochondrial membrane binding, J. Biol. Inorg. Chem., 15 (2010) 689-700. [19] M.J. Eddowes, H.A.O. Hill, Electrochemistry of horse heart cytochrome c, J. Am. Chem. Soc., 101 (1979) 4461-4464.

[20] M.J. Tarlov, E.F. Bowden, Electron-transfer reaction of cytochrome c adsorbed on carboxylic acid terminated alkanethiol monolayer electrodes, J. Am. Chem. Soc., 113 (1991) 1847-1849.

[21] X. Chen, R. Ferrigno, J. Yang, G.M. Whitesides, Redox Properties of Cytochrome c Adsorbed on Self-Assembled Monolayers: A Probe for Protein Conformation and Orientation, Langmuir, 18 (2002) 7009-7015.

[22] P. Hildebrandt, D.H. Murgida, Electron transfer dynamics of cytochrome c bound to selfassembled monolayers on silver electrodes, Bioelectrochemistry, 55 (2002) 139-143. 
[23] M.T. de Groot, T.H. Evers, M. Merkx, M.T.M. Koper, Electron Transfer and Ligand Binding to Cytochrome c' Immobilized on Self-Assembled Monolayers, Langmuir, 23 (2007) $729-736$

[24] Y. Chen, X.J. Yang, L.R. Guo, B. Jin, X.H. Xia, L.M. Zheng, Direct electrochemistry of cytochrome c on a phosphonic acid terminated self-assembled monolayers, Talanta, 78 (2009) $248-252$.

[25] Z. Salamon, G. Tollin, Interaction of horse heart cytochrome c with lipid bilayer membranes: effects on redox potentials, J. Bioenerg. Biomembr., 29 (1997) 211-221. [26] S. Boussaad, L. Dziri, R. Arechabaleta, N.J. Tao, R.M. Leblanc, Electron-Transfer Properties of Cytochrome c Langmuir-Blodgett Films and Interactions of Cytochrome c with Lipids, Langmuir, 14 (1998) 6215-6219.

[27] H. Park, J.-S. Park, Y.-B. Shim, Electrochemical and in situ UV-visible spectroscopic behavior of cytochrome c at a cardiolipin-modified electrode, J. Electroanal. Chem., 514 (2001) 67-74.

[28] Y. Huang, L. Liu, C. Shi, J. Huang, G. Li, Electrochemical analysis of the effect of Ca2+ on cardiolipin-cytochrome c interaction, Biochim. Biophys. Acta, 1760 (2006) 1827-1830. [29] S.E. Creager, T.T. Wooster, A New Way of Using ac Voltammetry To Study Redox Kinetics in Electroactive Monolayers, Anal. Chem., 70 (1998) 4257-4263.

[30] J. Li, K. Schuler, S.E. Creager, A Generalized Equivalent-Circuit Model for Electroactive Monolayers Exhibiting a Fixed Redox Potential and a Distribution of ElectronTransfer Rate Constants I. Square Distributions, J. Electrochem. Soc., 147 (2000) 4584-4588. [31] Y. Marty, F. Delaunay, J. Moal, J.F. Samain, Changes in the fatty acid composition of Pecten maximus (L.) during larval development, J. Exp. Mar. Biol. Ecol., 163 (1992) 221234. 
[32] K. Shin, T. Fujiwara, H. Akutsu, Modulation of the specific interaction of cardiolipin with cytochrome $\mathrm{c}$ by zwitterionic phospholipids in binary mixed bilayers; a $2 \mathrm{H}$ and $31 \mathrm{P}$ NMR study, J. Mol. Struct., 355 (1995) 47-53.

[33] H.O. Finklea, D.A. Snider, J. Fedyk, E. Sabatani, Y. Gafni, I. Rubinstein, Characterization of octadecanethiol-coated gold electrodes as microarray electrodes by cyclic voltammetry and ac impedance spectroscopy, Langmuir, 9 (1993) 3660-3667.

[34] S. Todorovic, C. Jung, P. Hildebrandt, D. Murgida, Conformational transitions and redox potential shifts of cytochrome P450 induced by immobilization, J. Biol. Inorg. Chem., 11 (2006) 119-127.

[35] S. Monari, D. Millo, A. Ranieri, G. Di Rocco, G. van der Zwan, C. Gooijer, S. Peressini, C. Tavagnacco, P. Hildebrandt, M. Borsari, The impact of urea-induced unfolding on the redox process of immobilised cytochrome c, J. Biol. Inorg. Chem., 15 (2010) 1233-1242. [36] T.J.T. Pinheiro, P.J. Bratt, I.H. Davis, D.C. Doetschman, A. Watts, Spin-lattice relaxation times of phospholipid aminoxyl spin labels in cardiolipin-cytochrome c bilayers: a pulse saturation-recovery EPR study, J. Chem. Soc. Perkin Trans. 2, 1993 (1993) 2113-2117. [37] P.K.J. Kinnunen, On the molecular-level mechanisms of peripheral protein-membrane interactions induced by lipids forming inverted non-lamellar phases, Chem. Phys. Lipids, 81 (1996) 151-166.

[38] G. McLendon, Long-distance electron transfer in proteins and model systems, Acc.Chem. Res., 21 (1988) 160-167. 


\section{Tables}

Table 1. Redox potential $\left(E_{1 / 2}\right)$, and the corresponding ET rate constant $\left(k_{\mathrm{ET}}\right)$ and cyt $c$ coverage $(I)$ calculated from ACV for the two different subpopulations of cyt $c$ immobilized either on a CL14:0- or a CL 18:2-modified electrode. The mean values of $E_{1 / 2}, k_{\mathrm{ET}}$ and $\Gamma$ were extracted from four (CL14:0) and seven (CL18:2) independent measures (see text).

\begin{tabular}{llll}
\hline Lipid film & $\boldsymbol{E}_{\mathbf{1 / 2}}(\mathbf{V}$ vs. SCE $)$ & $\boldsymbol{k}_{\mathbf{E T}}\left(\mathbf{s}^{\mathbf{- 1}}\right)$ & $\boldsymbol{\Gamma}\left(\mathbf{p m o l ~ \mathbf { ~ m } ^ { - \mathbf { 2 } } )}\right.$ \\
\hline CL14:0 & & & \\
Subpopulation 1 & $-0.010 \pm 0.006$ & $30 \pm 11$ & $5.2 \pm 2.5$ \\
Subpopulation 2 & $-0.120 \pm 0.009$ & $306 \pm 9$ & $0.9 \pm 0.1$ \\
CL18:2 & & & \\
Subpopulation 1 & $-0.020 \pm 0.004$ & $8 \pm 2$ & $8.1 \pm 3.1$ \\
Subpopulation 2 & $-0.141 \pm 0.008$ & $689 \pm 64$ & $0.4 \pm 0.1$ \\
\hline
\end{tabular}




\section{Figure captions}

Fig. 1. Topographic (left) and error amplitude (right) AFM images. Same spot on the electrode before (A) and after (B) deposition of a CL/PC film. Small patches of bilayer characterized by a relative height of $2 \mathrm{~nm}$ can be observed at the bottom left.

Fig. 2. Representative examples of voltammograms recorded at a bare GC electrode (dotted trace) and a CL/PC-modified GC electrode (dashed trace) in a solution containing $50 \mu \mathrm{M}$ cyt $c$ and $20 \mathrm{mM}$ TRIS-HCl (pH 7). The voltammogram recorded for the same lipid-modified GC electrode after transfer in a $20 \mathrm{mM}$ TRIS- $\mathrm{HCl}$ buffer solution that does not contain cyt $c$ is also shown (solid trace).

Fig. 3. Representative AC voltammograms recorded at frequencies ranging from 4 to $692 \mathrm{~Hz}$ for cyt c immobilized on a CL/PC-modified GC electrode in a $20 \mathrm{mM}$ TRIS-HCl buffer solution ( $\mathrm{pH} 7)$. Data are background corrected.

Fig. 4. AC voltammograms recorded at a frequency of $24 \mathrm{~Hz}$ for cyt $c$ immobilized on a CL/PC-modified electrode before (open squares) and after (open triangles) washing with 0.5 $\mathrm{M} \mathrm{KCl}$ solution. 

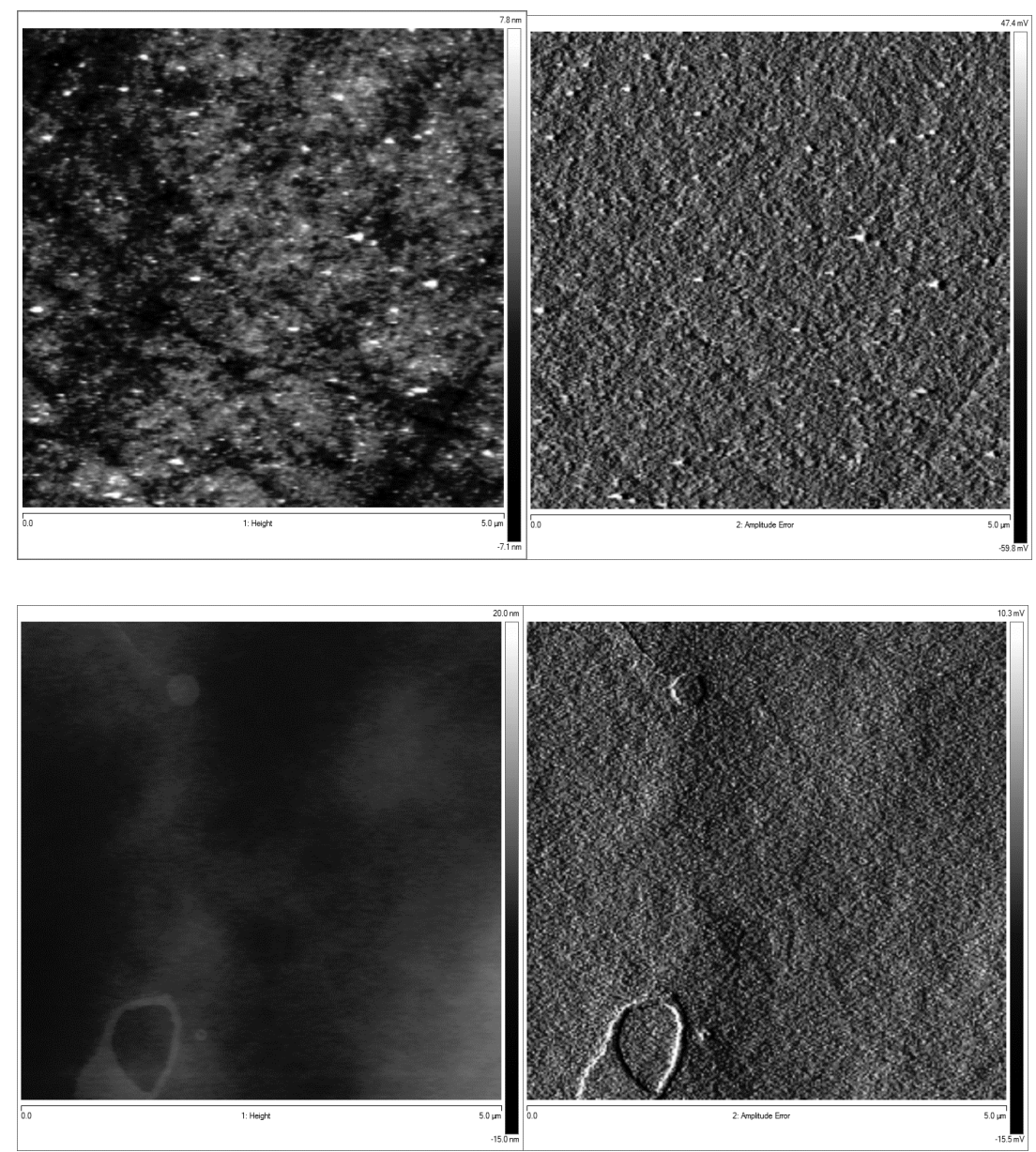

Fig. 1. Topographic (left) and error amplitude (right) AFM images. Same spot on the electrode before (A) and after (B) deposition of a CL/PC film. Small patches of bilayer characterized by a relative height of $2 \mathrm{~nm}$ can be observed at the bottom left. 


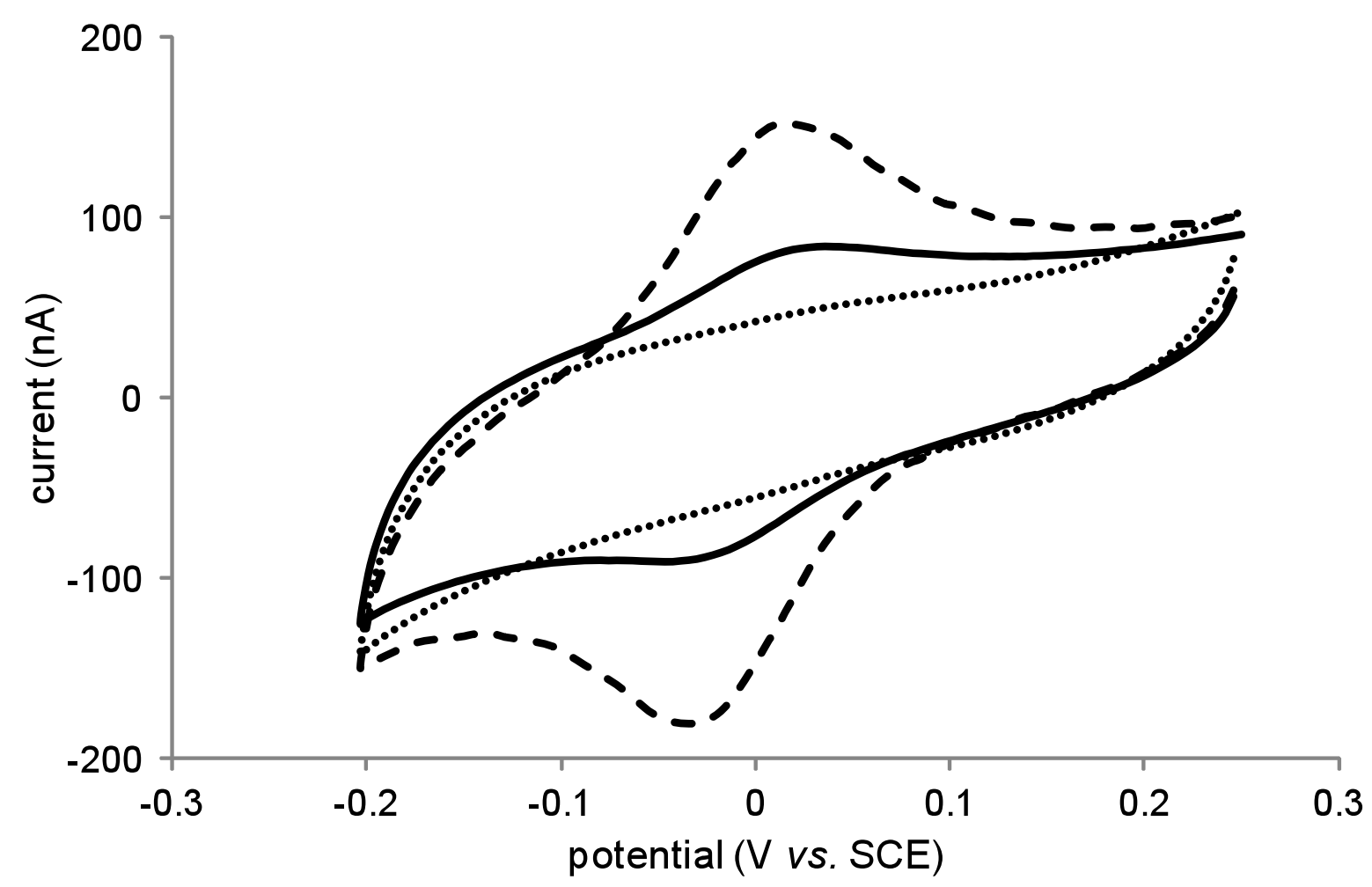

Fig. 2. Representative examples of voltammograms recorded at a bare GC electrode (dotted trace) and a CL/PC-modified GC electrode (dashed trace) in a solution containing $50 \mu \mathrm{M}$ cyt $c$ and $20 \mathrm{mM}$ TRIS-HCl ( $\mathrm{pH}$ 7). The voltammogram recorded for the same lipid-modified GC electrode after transfer in a $20 \mathrm{mM}$ TRIS-HCl buffer solution that does not contain cyt $c$ is also shown (solid trace). 


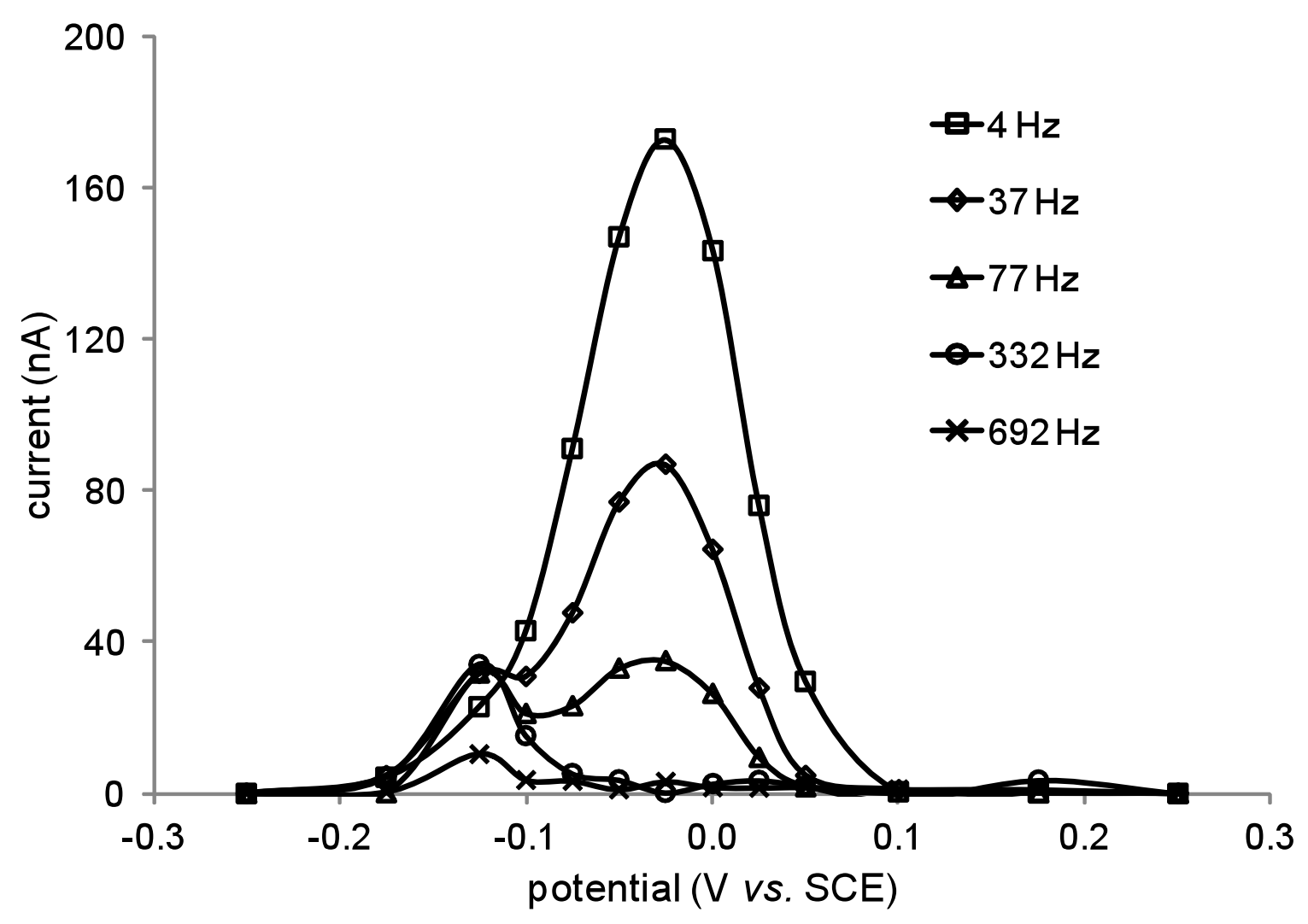

Fig. 3. Representative $\mathrm{AC}$ voltammograms recorded at frequencies ranging from 4 to $692 \mathrm{~Hz}$ for cyt c immobilized on a CL/PC-modified GC electrode in a $20 \mathrm{mM}$ TRIS-HCl buffer solution (pH 7). Data are background corrected. 


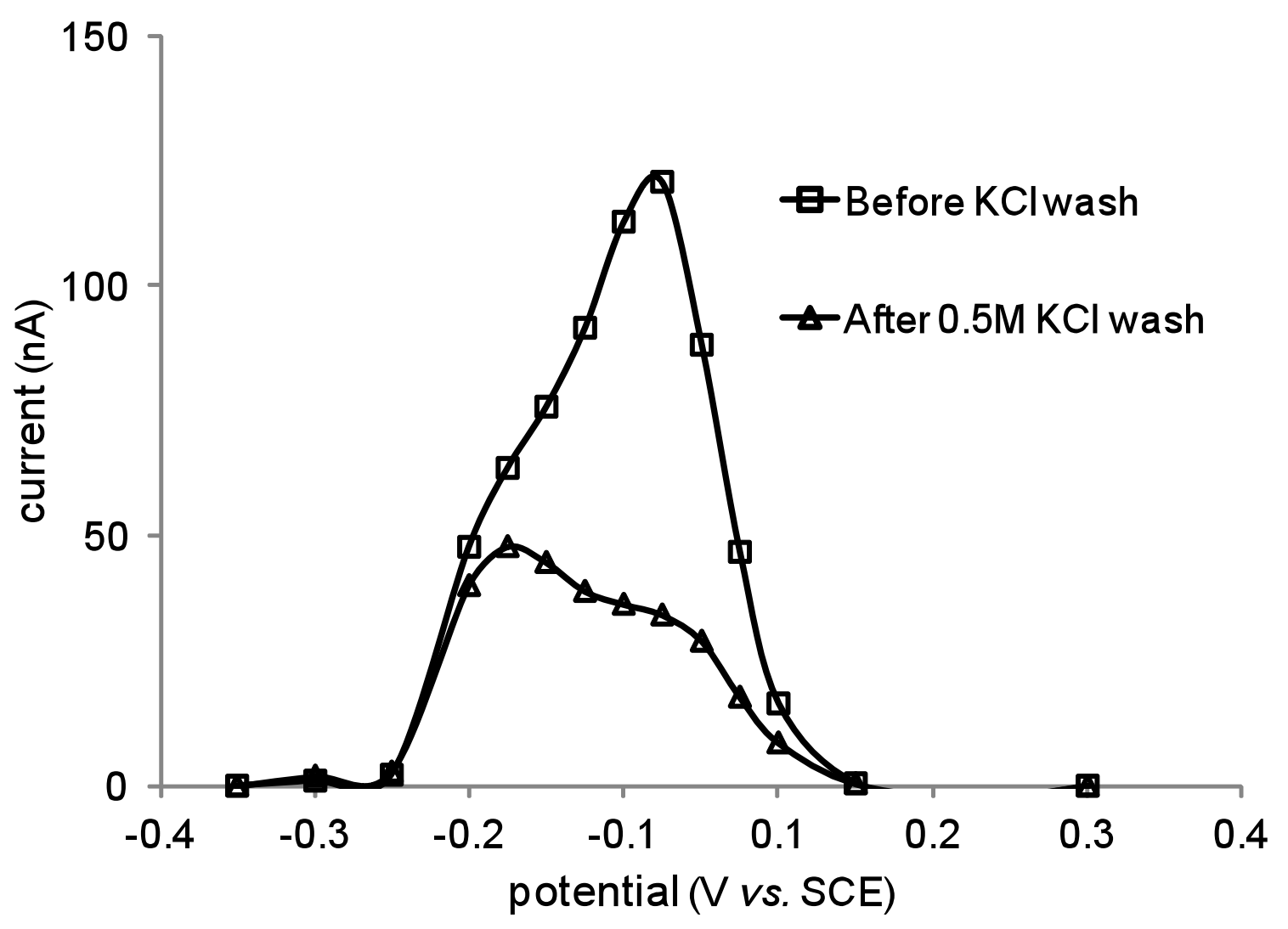

Fig. 4. AC voltammograms recorded at a frequency of $24 \mathrm{~Hz}$ for cyt $c$ immobilized on a CL/PC-modified electrode before (open squares) and after (open triangles) washing with 0.5 $\mathrm{M} \mathrm{KCl}$ solution. 